\title{
Upregulation of p38 pathway accelerates proliferation and migration of MDA-MB-231 breast cancer cells
}

\author{
HUGO W. HUTH ${ }^{1,2}$, DANIEL M. SANTOS ${ }^{3}$, HUMBERTO D. GRAVINA ${ }^{3}$, JARBAS M. RESENDE ${ }^{4}$, \\ ALFREDO M. GOES ${ }^{3}$, MARIA ELENA DE LIMA ${ }^{3}$ and CATHERINE ROPERT ${ }^{3}$ \\ Departments of ${ }^{1}$ Physiology and Pharmacology, ${ }^{2}$ Morphology, ${ }^{3}$ Biochemistry and Immunology, \\ ${ }^{4}$ Chemistry, Federal University of Minas Gerais, Belo Horizonte, Minas Gerais 31270-910, Brazil
}

Received July 20, 2016; Accepted January 13, 2017

DOI: $10.3892 /$ or.2017.5452

\begin{abstract}
Tumor cells capture the signaling pathways used by normal tissue to promote their own survival and dissemination and among them, the NF- $\mathrm{B}$ and MAPK pathways (ERK, JNK and p38). MAPK activation has ambiguous effects on tumor cell fate depending on cell type, cancer stage and the engaged MAPK isoforms. A synthetic peptide named LyeTx II, derived from the venom of the Brazilian spider Lycosa erythrognatha, was capable of increasing MDA-MB231 aggressive breast cancer cell proliferation as indicated by MTT and BrdU (5-bromo-2'-deoxyuridine) incorporation assay and cell migration. A correlation has been established between the accelerated proliferation and migration observed in the presence of LyeTx II and the upregulation of p38 MAPK phosphorylation. The use of the selective inhibitor of $\mathrm{p} 38 \alpha / \beta$ (SB203580) abrogated the peptide effect in MDA-MB-231 cells. Besides, an augment of the canonical $\mathrm{NF}-\kappa \mathrm{B}$ pathway activation considered as crucial in cancer progression was noted after cell incubation with LyeTx II. Importantly, activation of p38 and NF- $\kappa$ B pathways was dependent on TAK1 activity. Together, these data suggest that TAK1-p38 pathway may represent an interesting target for treatment of aggressive breast cancers.
\end{abstract}

\section{Introduction}

Cancer is the second most common cause of death worldwide, preceded only by heart diseases (1). Breast cancer is one of the most common in women, with high morbidity. Generally,

Correspondence to: Dr Catherine Ropert, Departamento de Bioquimica e Imunologia, Instituto de Ciências Biológicas, Av. Antônio Carlos 6627 - Pampulha, Belo Horizonte, Minas Gerais 31270-910, Brazil

E-mail: ropertcatherine@gmail.com

Abbreviations: MAPK, mitogen-activated protein kinase

Key words: breast cancer, MDA-MB-231, MAPK, p38, proliferation, migration treatment occurs via surgery, chemotherapy, radiotherapy and immunotherapy. However, despite the various therapeutic strategies that can be adopted, the mortality rate and the side effects of the treatment remain a challenge $(2,3)$. Therefore, the search for new alternative treatments with less side effects is under investigation.

In such context, there is great interest in the pharmaceutical industry to target pathways that regulate cell proliferation and apoptosis in cancer. These pathways are initiated from various cell surface receptors, and may converge on the MAPK cascade, a module consisting of MAP kinase kinase (MEK) and MAPK (4-6). The MAPKs are serine/threonine protein kinases that participate in different intracellular processes such as proliferation, differentiation, cellular stress responses, and apoptosis $(7,8)$. ERK1/2, JNK1/2/3 and $\mathrm{p} 38 \alpha / \beta / \gamma / \delta$ constitute the main mammalian MAPKs studied in cancer area. ERK pathway is activated by mitogen factors, and this pathway is one of the most mutated in cancer often leading to an increase of cell proliferation and generally a decrease of apoptosis (9). On the other hand, p38 and JNK pathways are activated by stress factors, but their roles in cancer remain unclear, depending on cancer stage, cell type or MAPK isoforms (10-13).

Another pathway that called attention and has also been described as crucial in cancer progression is the $N F-\kappa B$ pathway $(14,15)$. The transcription factor $\mathrm{NF}-\kappa \mathrm{B}$ controls many intracellular signals including cell cycle (e.g. cyclin D1), suppression of apoptosis (e.g. Bcl-2 and Bcl-xL) and inflammation (e.g. IL-6) (16). In response to a wide variety of stimuli, $\mathrm{NF}-\kappa \mathrm{B}$ becomes active via canonical or non-canonical pathways in cancer. Generally, in the canonical pathway $\mathrm{NF}-\kappa \mathrm{B}$ activation is preceded by the phosphorylation of IKK- $\alpha \beta$ and $\mathrm{I} \kappa \mathrm{B} \alpha(17,18)$.

Nowadays, the major interest is to identify relevant molecular targets that may offer a specific therapeutic alternative treatment to cancer. In this context, MAPKs and NF- $\kappa \mathrm{B}$ pathways represent an interesting signaling network for investigation. In the present study, we used a peptide (named LyeTx II) derived from the venom of the spider Lycosa erythrognatha, that induced an exacerbated proliferation of MDA-MB-231 breast cancer cells, to evaluate the importance of the MAPKs and NF- $\mathrm{B}$ pathways in proliferation and migration of this breast cancer cell line considered as aggressive. According to our data, the proliferative and migratory 
effect induced by the peptide occurred mainly through upregulation of p38 pathway activation, without involvement of ERKs and JNKs. This study provides new insights into the role of p38 in aggressive breast tumor indicating that p38 may be a suitable target in this cancer type.

\section{Materials and methods}

Reagents. DMEM and fetal bovine serum (FBS) (Gibco) were from Thermo Fisher Scientific (Waltham, MA, USA). Thiazolyl Blue Tetrazolium Blue (MTT) and RIPA buffer were purchased from Sigma-Aldrich (St. Louis, MO, USA). p38 inhibitor SB203580 were obtained from InvivoGen (San Diego, CA, USA). Protease cocktail inhibitor and phosphatase cocktail inhibitor were acquired from Roche (Mannheim, Germany). Monoclonal antibodies against phospho-p44/42 (ERK1/2), phospho-p38 MAPK, phospho-JNK MAPK, $\beta$-actin and peroxidase-conjugated goat anti-mouse $\mathrm{IgG}$ and goat anti-rabbit IgG were obtained from Cell Signaling Technology (Danvers, MA, USA). Apoptosis, DNA Damage and Cell Proliferation Kit were obtained from BD Biosciences (Franklin Lakes, NJ, USA). Immobilon-P membranes and Luminat were acquired through Merck Millipore (Darmstadt, Germany).

Peptide information, synthesis and purification. LyeTx II is a 19 amino acid peptide, which includes four lysine residues conferring positive charge to it. LyeTx II synthesis and purification was performed at Professor J.M. Resende's Laboratory, from the Chemistry Department of UFMG, Brazil, according to methodology described by Santos et al (19). The purity of LyeTx II was checked by mass spectometry.

Cell culture conditions. The breast tumor cell lines MDA-MB-231 and MCF-7 were gifts from the Laboratory of Prof. A.M. Goes. MACL-1 and MGSO-3 cell lines were derived from primary tumor samples in the same laboratory (20). Cells were grown at $37^{\circ} \mathrm{C}$ in a humidified atmosphere of $5 \% \mathrm{CO}_{2}$ in DMEM supplemented with $10 \%$ heat inactivated FBS. For starvation conditions, cells were incubated with serum-free medium for $2 \mathrm{~h}$ before the western blot assay.

MTT assay. Breast cancer cells $\left(10^{4} /\right.$ well $)$ were plated in 24-well plates in DMEM with $10 \%$ serum. Cells were incubated for a further $96 \mathrm{~h}$ in the following conditions: medium alone, LyeTx II (from 0.1 to $100 \mathrm{nM}$ ), SB203580 (10 $\mu \mathrm{M}$ ). After $96 \mathrm{~h}$, the medium was removed and cells were incubated with $100 \mu \mathrm{l} /$ well of MTT at $5 \mathrm{mg} / \mathrm{ml}$ for $2 \mathrm{~h}$, at $37^{\circ} \mathrm{C}$. After removing the medium, $200 \mu 1$ of DMSO was added to dissolve the formazan crystals and the absorbance was measured in a microplate reader at a wavelength of $595 \mathrm{~nm}$. A value of $100 \%$ was assigned to untreated control cultures. Results were derived from at least three independent sets of triplicate experiments.

Western blotting. Cells seeded in 6-well plates $\left(10^{6}\right.$ cells/well) were serum-starved for $2 \mathrm{~h}$. Then, cells were treated or not with LyeTx II (100 nM) in DMEM containing 10\% FBS for the indicated time-points. 5z-7-oxozeaenol was added $30 \mathrm{~min}$ before the addition of LyeTx II. Cells were harvested and lysed in RIPA buffer supplemented with phosphatase inhibitor and protease inhibitor cocktail according to the manufacturer's instructions. Protein lysates were separated by polyacrylamide gel electrophoresis on $12 \%$ gels, and electrotransferred to Immobilon-P membranes. Membranes were incubated with primary antibodies. After incubation with peroxidaseconjugated secondary antibody, protein expression was detected using Luminat reagent.

Measurement of cell proliferation by BrdU incorporation. This assay was realized using the Apoptosis, DNA Damage, and Cell Proliferation kit from BD Biosciences in accord with the manufacturer's instructions. Briefly, cells were treated or not with LyeTx II (100 nM) in DMEM containing 10\% FBS and incubated with BrdU $(10 \mu \mathrm{M})$ for $8 \mathrm{~h}$. When used, SB203580 was added $30 \mathrm{~min}$ before the addition of LyeTx II. After labeling, cells were fixed and permeabilized. After several washing, cells were treated with DNase ( $30 \mu \mathrm{g} / 10^{6}$ cell) for $1 \mathrm{~h}$. Following this treatment, cells were simultaneously stained with PerCP-Cy ${ }^{\mathrm{TM}} 5.5$ anti-BrdU and Alexa-647 anti- $\gamma \mathrm{H} 2 \mathrm{AX}$ for $20 \mathrm{~min}$ at room temperature. After washing, cells were suspended in staining buffer and analyzed by flow cytometry. The data were collected by the cell analyzing LSRFortessa (BD Biosciences - Immunocytometry Systems) using BD FACSDiva $^{\mathrm{TM}}$ software (BD Biosciences) and analyzed with FlowJo (Tree Star) software.

Cell counting. Cells were seeded in a density of $1 \times 10^{4}$ cells/well in 24-well plates. Cells were treated with LyeTx II $(100 \mathrm{nM})$ in DMEM containing 10\% FBS and incubated for $24,48,72$ and $96 \mathrm{~h}$. In each time, cells were harvested, stained with Tripan Blue (Gibco) and then counted in Neubauer plate. Number of cells $=$ media of three counting $\times 10^{4} / \mathrm{ml}$.

Transwell assay. The 24-well Boyden chamber with $8 \mu \mathrm{m}$ pore size polycarbonate membrane Millipore (Millicell Hanging Cell Culture Inserts, Millipore, EUA) was used to analyze cell motility. For invasion assay, the membrane was pre-coated for $1 \mathrm{~h}$ with $300 \mu \mathrm{l}$ of free serum DMEM. Cells $\left(10^{6}\right)$ were seeded on the upper chamber with serum-free medium with or without LyeTx II (100 nM). When used, SB203580 (10 $\mu \mathrm{M})$ was added $30 \mathrm{~min}$ before LyeTx II addition also in the upper chamber. Medium $700 \mu 1$ (or until the volume reaches the upper chamber membrane) with $10 \%$ serum was added to the lower chamber as a chemoattractant. After $24 \mathrm{~h}$ of incubation, the non-motile cells at the top of the membranes were removed with cotton swabs, then the membranes were fixed and stained with $0.5 \%$ crystal violet (Sigma). Five visual fields of x200 magnification of each membrane were randomly selected and counted.

\section{Results}

Peptide LyeTx II enhances MDA-MB-231 cell population growth. Without initial information about LyeTx II activity, we predicted that this peptide, derived from the venom of the Brazilian spider Lycosa erythrognatha, could interact with the anionic membrane of the cancer cells due to its amino acid composition (four lysine residues conferring positive charge) and its secondary structure ( $\alpha$-helix). Therefore, we have evaluated the effect of the peptide on four different breast cancer 
A

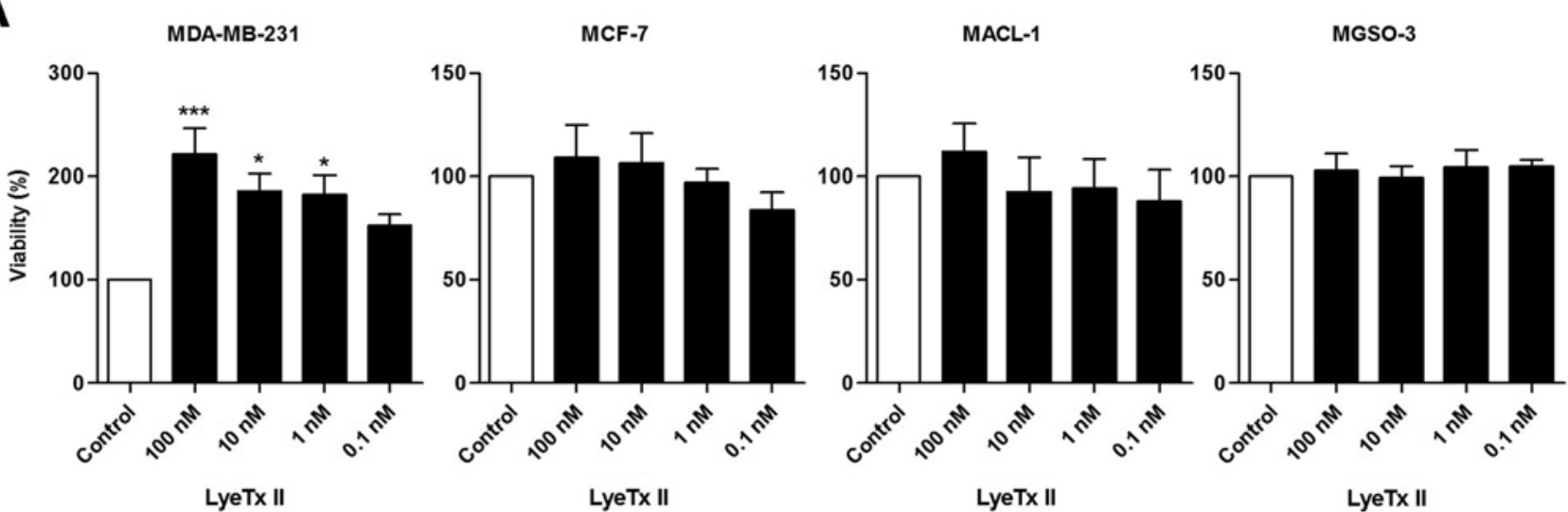

B

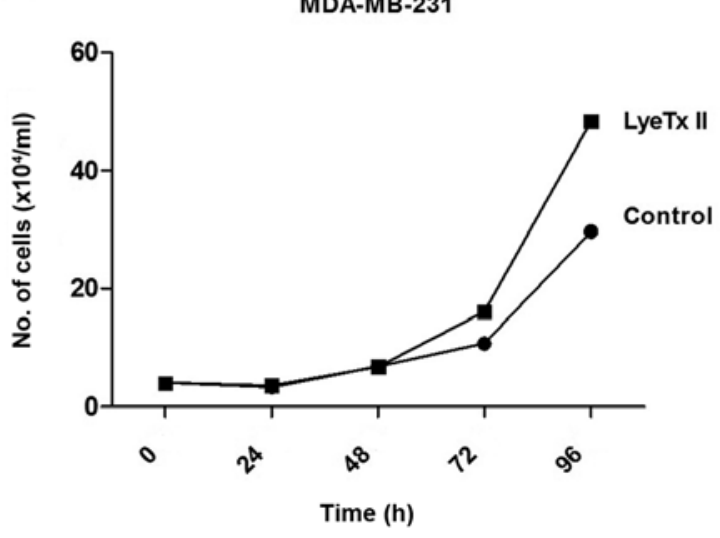

Figure 1. The peptide LyeTx II increases the proliferation of MDA-MB-231 cells. (A) Cell viability of breast cancer cell lines (MDA-MB-231, MCF-7, MACL-1, MGSO-3) was measured by MTT assay. "p $<0.05 ; * * * 00.01$. MTT assay was performed after $96 \mathrm{~h}$ of incubation in DMEM supplemented with $10 \%$ of FBS in the presence or not of LyeTx II at different concentrations. (B) Growth curve of MDA-MB-231 cells was realized in the presence of $100 \mathrm{nM}$ of LyeTx II during $96 \mathrm{~h}$ and cell counting was performed at each $24 \mathrm{~h}$. Statistical analyses were performed using one-way ANOVA followed by Bonferroni post test.

cell lines (MDA-MB-231, MCF-7, MACL-1 and MGSO-3). Cells were incubated with different peptide concentrations varying from 0.1 to $100 \mathrm{nM}$ and an MTT assay was performed to evaluate cell viability (Fig. 1A). Of note, LyeTx II induced an increase of MDA-MB-231 cell viability after 4 days and this effect was more marked at $100 \mathrm{nM}$. No effect induced by the peptide was observed on the other breast cancer cell lines indicating that only the most aggressive cell line was responsive to LyeTx II. As MTT assay measures viable cell metabolism and not specifically cell proliferation, we confirmed our data by cell counting. According to Fig. 1B, an increased cell number was noted after 72 and $96 \mathrm{~h}$ of treatment with LyeTx II when compared to the control group.

Peptide LyeTx II enhances MDA-MB-231 cell proliferation. We sought to define whether the increased cell number observed in the presence of LyeTx II after $96 \mathrm{~h}$ was due to a direct activation of the proliferative machinery or liberation of secondary compounds. For this purpose, a BrdU assay was performed, that allowed us to correlate the proliferative effect induced by the peptide and the incorporation of BrdU that is a synthetic nucleoside analog of thymidine. Firstly, we pregated cells according to size (SSC) and granulometry (FSC). To select the population in division, H2AX in its phosphorylated form $(\gamma \mathrm{H} 2 \mathrm{AX})$ has been used as a marker of the DNA doubled stranded breaks. The detection of the incorporation of BrdU and the presence of $\gamma \mathrm{H} 2 \mathrm{AX}$ has been achieved by using antibody stained with PerCP-Cy5.5 and Alexa-647, respectively. As shown in the Fig. 2A, by double immunodetection, after $8 \mathrm{~h}$ of incubation with LyeTx II and BrdU, augmentation of the $\mathrm{BrdU}^{+} / \gamma \mathrm{H} 2 \mathrm{AX}^{+}$population was noted when compared with the control cell population. The $\mathrm{BrdU}^{+} / \gamma \mathrm{H}_{2} \mathrm{AX}^{+}$population increased from 6.9 to $11.0 \%$ (Fig. 2B). Taken together, these data suggest that LyeTx II is able to interfere directly on the proliferative machinery of MDA-MB-231 cells. These findings led us to investigate the intracellular signaling pathways involved in the increased proliferation induced by LyeTx II.

p38 and NF- $\kappa B$ pathway activation are upregulated in the presence of LyeTx II. Considering that MAPKs are frequently involved in the balance between cell proliferation and cell death, we sought to evaluate the phosphorylation state of the three main MAPKs (ERKs, JNKs and p38s) in the presence of LyeTx II (Fig. 3A). LPS $(1 \mu \mathrm{g} / \mathrm{ml})$ and TNF- $\alpha(20 \mathrm{pg} / \mathrm{ml})$ were used as positive control for the MAPK phosphorylation. At first, we observed that MDA-MB-231 cells did not use the JNK pathway, not in the presence of serum or in the presence of the peptide. However, we verified, that MDA-MB-231 cells 
A

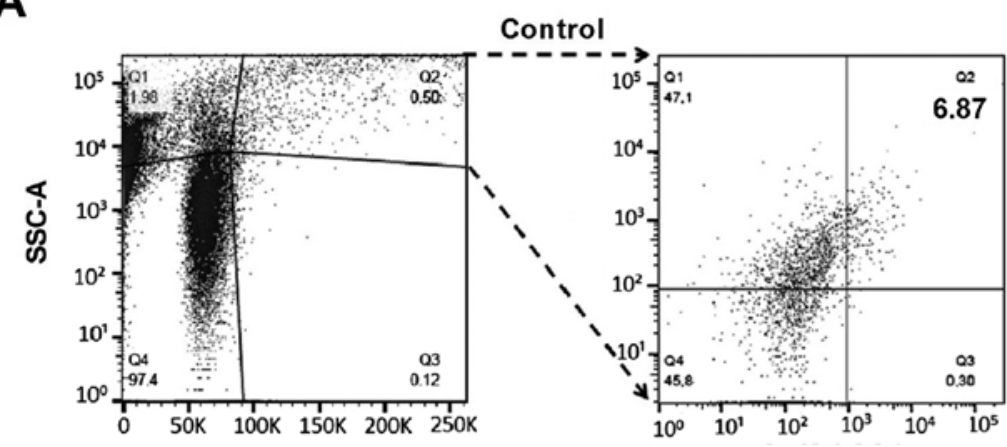

LyeTx II

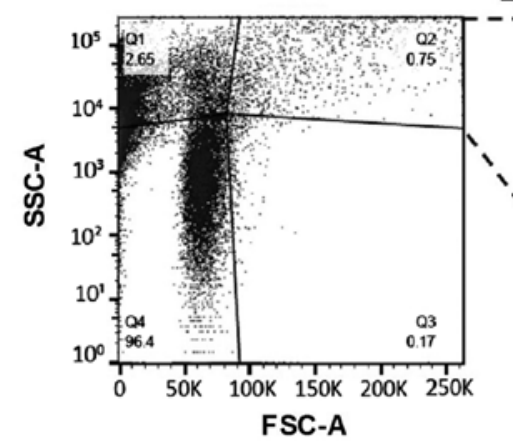

B

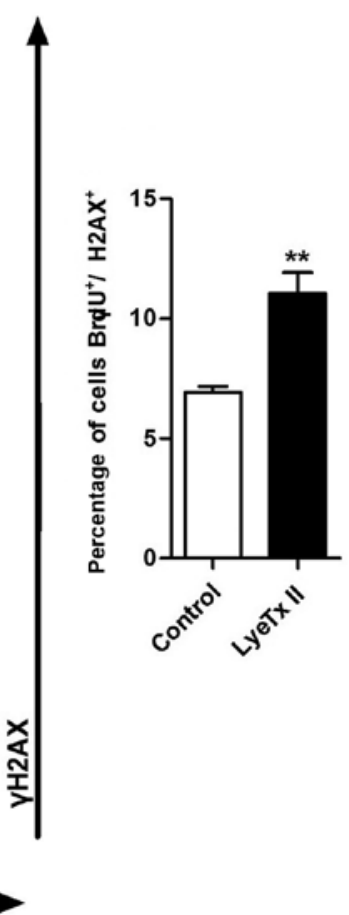

Figure 2. The peptide LyeTx II augments BrdU incorporation in MDA-MB-231 cells. MDA-MB-231 cells were incubated in DMEM with $10 \%$ of FBS and treated with LyeTx II $(100 \mathrm{nM})$ and $\mathrm{BrdU}(10 \mu \mathrm{M})$ for $8 \mathrm{~h}$. Then, cells were fixed, permeabilized and stained with anti-BrdU and anti- $\gamma \mathrm{H} 2 \mathrm{AX}$ and analyzed by FACS. Data are presented as (A) the representative dot plots of the frequency of individual data values and (B) the frequency of $\mathrm{BrdU}^{+} / \gamma \mathrm{H}_{2} \mathrm{AX} \mathrm{X}^{+}$cells (average $\pm \mathrm{SD}$ ). Data are representative of two independent experiments in triplicate. Statistical analyses were performed using t-test. ${ }^{* * *} \mathrm{p}<0.01$.

A
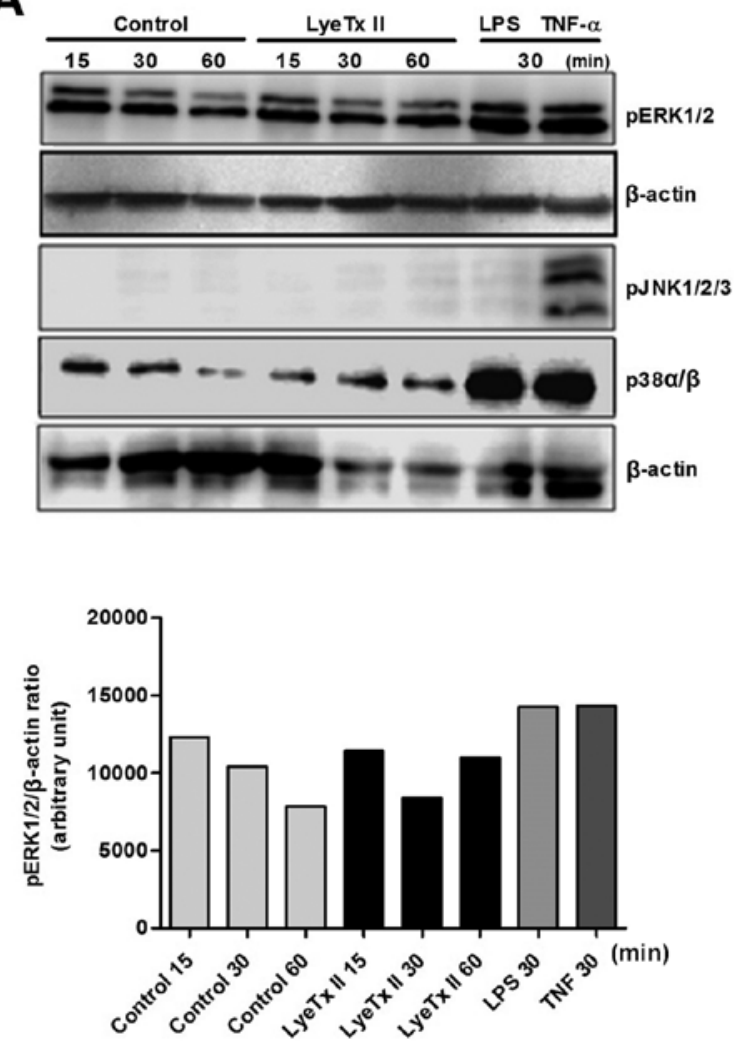

B
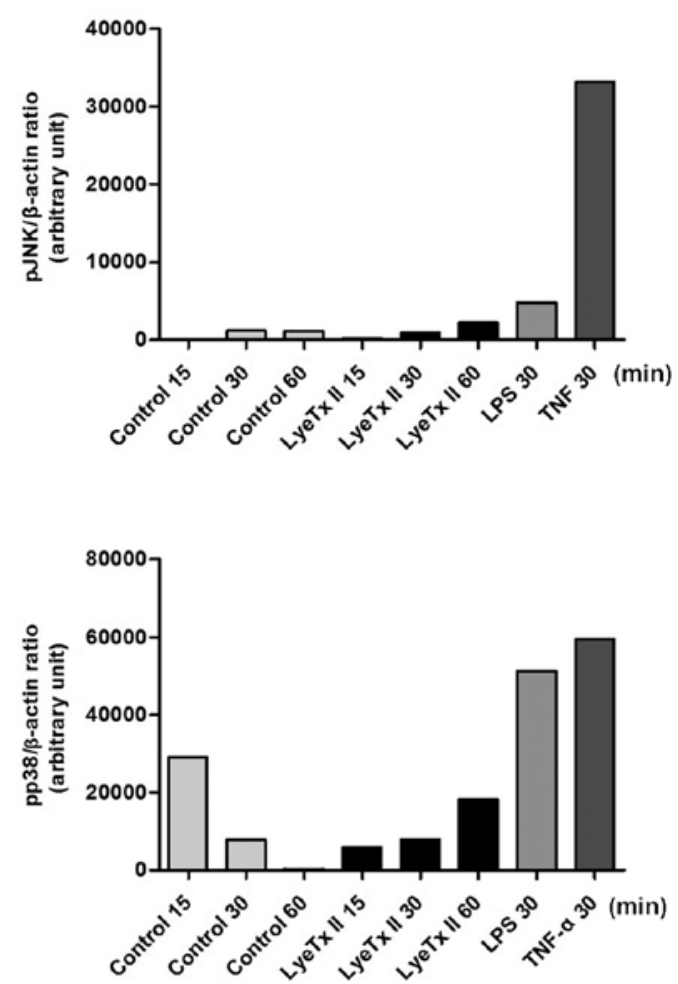

Figure 3. The peptide LyeTx II modulates p38 pathway activation in MDA-MB-231 cells. (A) MDA-MB-231 cells were incubated for 15, 30 and 60 min with LyeTx II at $100 \mathrm{nM}$ in DMEM supplemented with 10\% FBS (Control = medium 10\% FBS). Then, cells were harvested and cell lysates were immunobloted with the indicated antibodies. LPS $(1 \mu \mathrm{g} / \mathrm{ml})$ and TNF- $\alpha(20 \mathrm{pg} / \mathrm{ml})$ were used as positive controls. (B) The graphics represent the level of proteins quantified and normalized to the level of $\beta$-actin. 
A

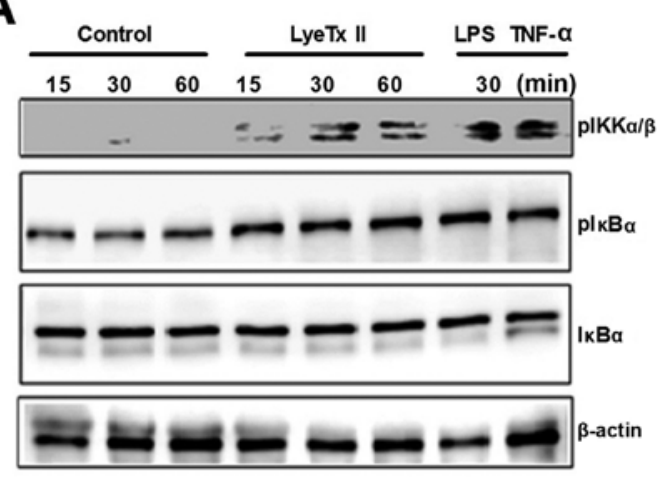

B
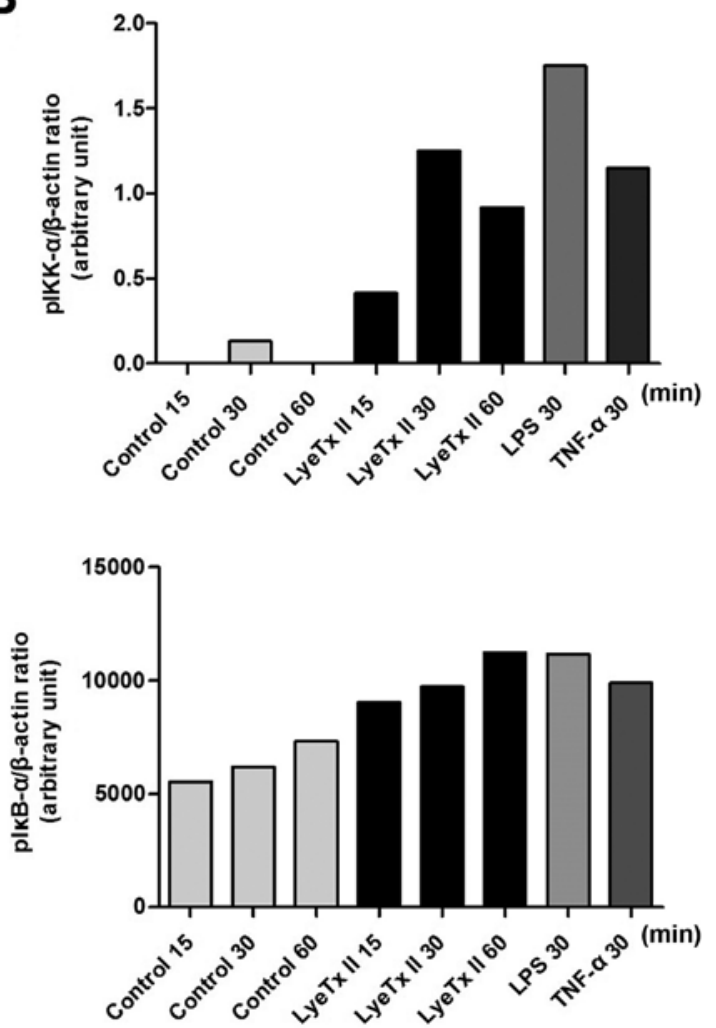

Figure 4. The peptide LyeTx II increases NF- $\mathrm{B}$ pathway activation in MDA-MB-231 cells. (A) MDA-MB-231 cells were incubated for 15, 30 and 60 min with LyeTx II at $100 \mathrm{nM}$ in DMEM supplemented with $10 \%$ FBS $($ Control $=$ medium $10 \%$ FBS $)$. Then, cells were harvested and cell lysates were immunobloted with the indicated antibodies. LPS $(1 \mu \mathrm{g} / \mathrm{ml})$ and TNF- $\alpha$ $(20 \mathrm{pg} / \mathrm{ml})$ were used as positive control. (B) The graphics represent the level of proteins quantified and normalized to the level of $\beta$-actin.

were able to phosphorylate JNK1/2/3 under stress stimulation when TNF- $\alpha$ induced activation of the three isoforms of JNK. This constitued a direct evidence that LyeTx II did not require JNK activation to induce its proliferative effect. Concerning ERK1/2 pathway, no significant change in the kinetic phosphorylation of this MAPK was detected in the presence of LyeTx II. The most significant impact induced by the peptide was the modulation of p38 phosphorylation. We observed that the phosphorylation of p38 was upregulated during stimulation with LyeTx II, suggesting that the peptide effect might be related to p38 pathway activation. As shown in the Fig. 3A, phosphorylation of p38 remained elevated when compared to control group, even 60 min after peptide stimulation.
In parallel, we explored the $\mathrm{NF}-\kappa \mathrm{B}$ pathway, another pathway well described as having an important role in cancer development. As shown in Fig. 4A, the peptide was able to enhance I $\kappa \mathrm{B} \alpha$ phosphorylation as well as IKK- $\alpha \beta$, two of the main kinases involved in the canonical NF- $\mathrm{NB}$ pathway activation. These data suggest a possible involvement of $N F-\kappa B$ pathway in MDA-MB-231 cell proliferation under stimulation with LyeTx II.

Upregulation of p38 pathway is associated with the accelerated proliferation of $M D A-M B-231$ in the presence of LyeTx II. To evaluate whether the peptide effect was dependent on $\mathrm{I} \kappa \mathrm{B} \alpha$ and $\mathrm{p} 38$ activation, we used two selective inhibitors: BAY 11-7082 for NF- $\kappa$ B pathway (21) and SB203580 for p38 pathway (22). It was not possible to define the involvement of $\mathrm{NF}-\kappa \mathrm{B}$ pathway in the peptide activity, since $\mathrm{I} \kappa \mathrm{B} \alpha$ inhibitor induced MDA-MB-231 cell death in the concentration range used (2.5-20 $\mu \mathrm{M})$, that represent the concentrations able to inhibit I $\kappa \mathrm{B} \alpha$ activity as previously reported (21). To correlate the peptide effect with the $\mathrm{p} 38$ pathway activation, we performed an MTT assay using SB203580 at concentration that did not affect the basal cell proliferation in our system. As shown in Fig. 5C, SB203580 was able to abrogate the proliferative effect induced by the peptide. To confirm the relationship between p38 activation and the proliferative effect induced by the peptide, we evaluated the BrdU incorporation in the presence of LyeTx II, SB203580 and SB203580 plus LyeTx II (Fig. 5A and B). Corroborating with the MTT assay, SB203580 was able to abolish the peptide effect maintaining the proliferative rate at a basal level. More precisely, in the presence of SB203580, the frequency of BrdU ${ }^{+}$cells was significantly reduced in LyeTx II group comparing with LyeTx II group pretreated with SB203580. Collectively, the data confirmed that p38 plays a role in the increase of MDA-MB-231 cell proliferation when stimulated with LyeTx II.

p38 pathway upregulation is associated with the increased migration of MDA-MB-231 cells in the presence of LyeTx II. We hypothesized that accelerated proliferation and migration events might share the same signaling pathways in MDA-MB-231 cells. In such context, we evaluated whether the peptide could increase MDA-MB-231 cell migration by using the transwell assay. By placing the cells on one side of the membrane and using FBS as a chemoattractant on the other side, migration was determined by counting those cells that traversed the cell-permeable membrane. As shown in Fig. 6A and B, LyeTx II at $100 \mathrm{nM}$ was also capable of enhancing cell migration in a significant way when compared to the control group. It is important to note that MDA-MB-231 cell line is considered as invasive, that explains the high number of cells that can pass through the membrane pores observed in serum conditions. The involvement of $\mathrm{p} 38$ pathway in MDA-MB231 cell migration was confirmed when it was shown that SB203580 reduced the peptide effect on cell migration.

p38 and I $\kappa$ B $\alpha$ phosphorylation induced by LyeTx II is dependent on TAK1. According to our data, LyeTx II was able to upregulate $\mathrm{p} 38$ and $\mathrm{NF}-\kappa \mathrm{B}$ pathway activation, so we sought to determine possible crosstalk between these pathways. TAK1 has been previously described as a common upstream kinase 
A

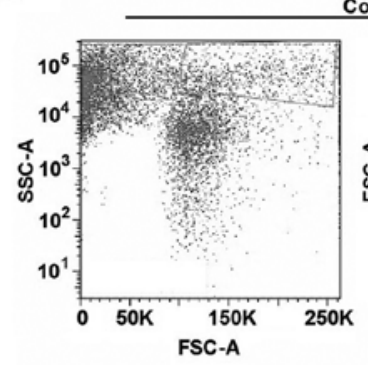

Control

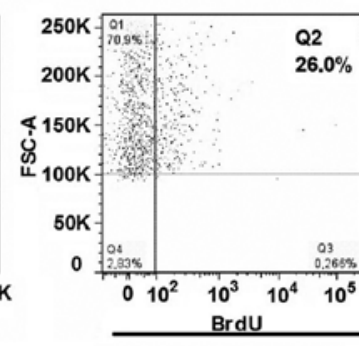

SB203580

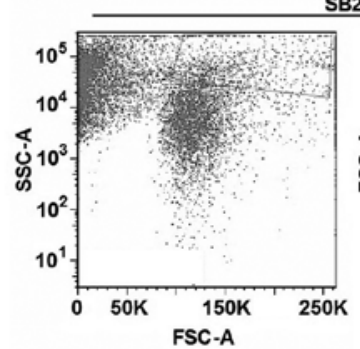

B

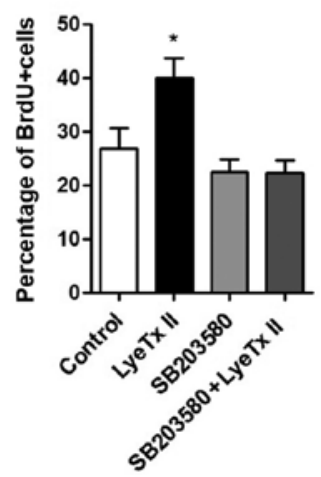

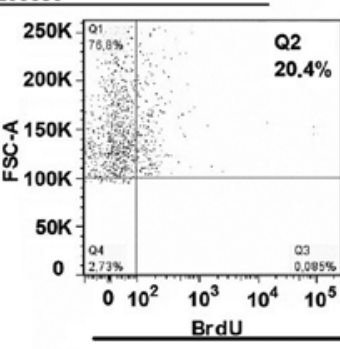

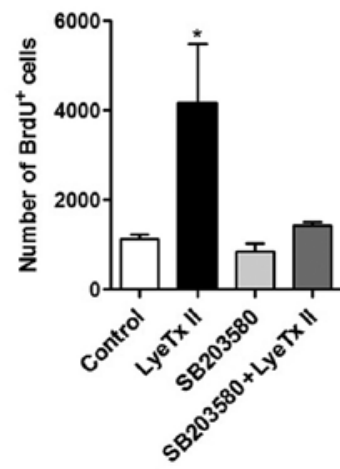

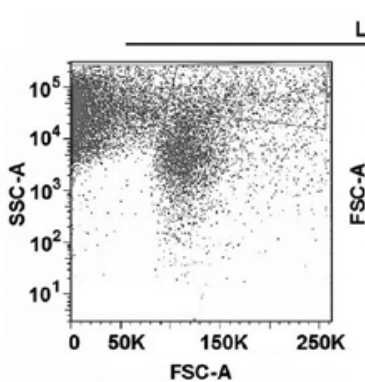

Lye Tx II

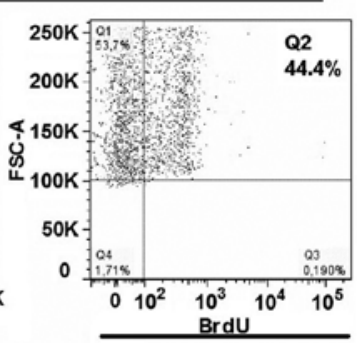

SB203580+LyeTX II
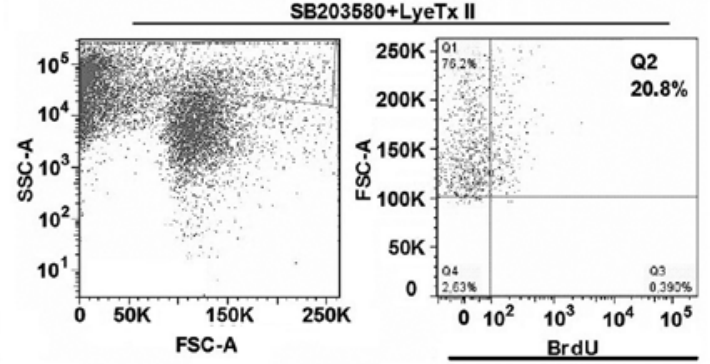

C

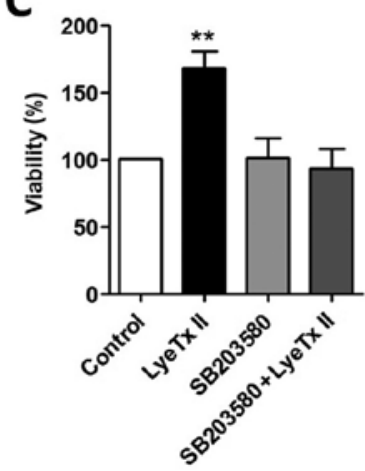

Figure 5. p38 inhibitor abrogates LyeTx II effect on MDA-MB-231 cell proliferation. (A) Cells incubated in DMEM supplemented with 10\% of FBS were treated with LyeTx II $(100 \mathrm{nM})$ and BrdU $(10 \mu \mathrm{M})$ for $8 \mathrm{~h}$, pretreated or not with p38 inhibitor SB203580 $(10 \mu \mathrm{M})$ for 30 min. Then, cells were stained with fluorescent antibodies anti-BrdU and analyzed by FACS. Data are presented as (A) the representative dot plots of the frequency of individual data values and (B) the frequency and the number of BrdU ${ }^{+}$cells (average \pm SD). (C) Cell viability was measured by MTT assay after incubation for $96 \mathrm{~h}$ with LyeTx II pretreated or not with SB203580 $(10 \mu \mathrm{M})$ for 30 min. Control group (NT) represents cells incubated with medium supplemented with $10 \%$ FBS. MTT data are representative of three experiments. Statistical analyses were performed using one-way ANOVA followed by Bonferroni post test. ${ }^{*} \mathrm{p}<0.05$; ${ }^{* *} \mathrm{p}<0.01$.

for both pathways (23). Further, other groups have previously described the involvement of TAK1 in the MDA-MB-231 cell survival $(24,25)$. Thus, we explored the impact of TAK1 inhibition on the peptide effect. As shown in Fig. 7, when cells were stimulated with the peptide, they were still able to phosphorylate $\mathrm{p} 38$ and $\mathrm{I \kappa B} \alpha$ in the presence of TAK1 at $300 \mathrm{nM}$. However, at $500 \mathrm{nM}$, TAK1 inhibitor reduced significantly p38 and IкB $\alpha$ phosphorylation in LyeTx II-treated cells. Taken together, these data indicate that LyeTx II upregulates p38 and NF- $\kappa B$ pathways in a TAK1-dependent manner.

\section{Discussion}

A peptide derived from the venom of the Brazilian spider Lycosa erythrognatha was used to correlate activated signaling pathways and aggressive breast cancer cell proliferation. There are several studies describing p 38 as a proliferative agent $(26,27)$; on the other hand, some studies have defined p38 as an apoptosis inducer (28-30). Herein, we clearly defined that p38 was involved in the peptide induced-MDA-MB-231 cell gain functions such as proliferation and migration.
Further, these data show a direct role for p38 in the cell cycle since the use of p38 inhibitor SB203580 abrogates the peptide effect on the BrdU incorporation in the first hours. In fact, it has been previously reported that p38 may regulate both the G2/M as well as G1/S cell cycle checkpoints (31-33). Different hypothesis may be advanced like the upregulation of cyclin D1 expression in a p38-dependent manner (34) or an additional mechanism that may contribute to augmentation of proliferation in the presence of the peptide. As p38 has also a well-known role in inflammation (35), we investigated a possible role of inflammatory mediators in the peptide effect. Since no augmentation of cytokine secretion was observed in the presence of LyeTx II, we were able to discard the correlation between the pro-inflammatory property of $\mathrm{p} 38$ and the peptide activity (data not shown). In addition, the use of rhTNF- $\alpha$ at a very low concentration $(20 \mathrm{pg} / \mathrm{ml})$ enhanced MDA-MB-231 proliferation (data not shown) and MAPK phosphorylation (including ERK and JNK) in a more pronounced way than the peptide. Taken together, these data support the idea that the proliferation effect induced by LyeTx II is independent on inflammatory processes. 

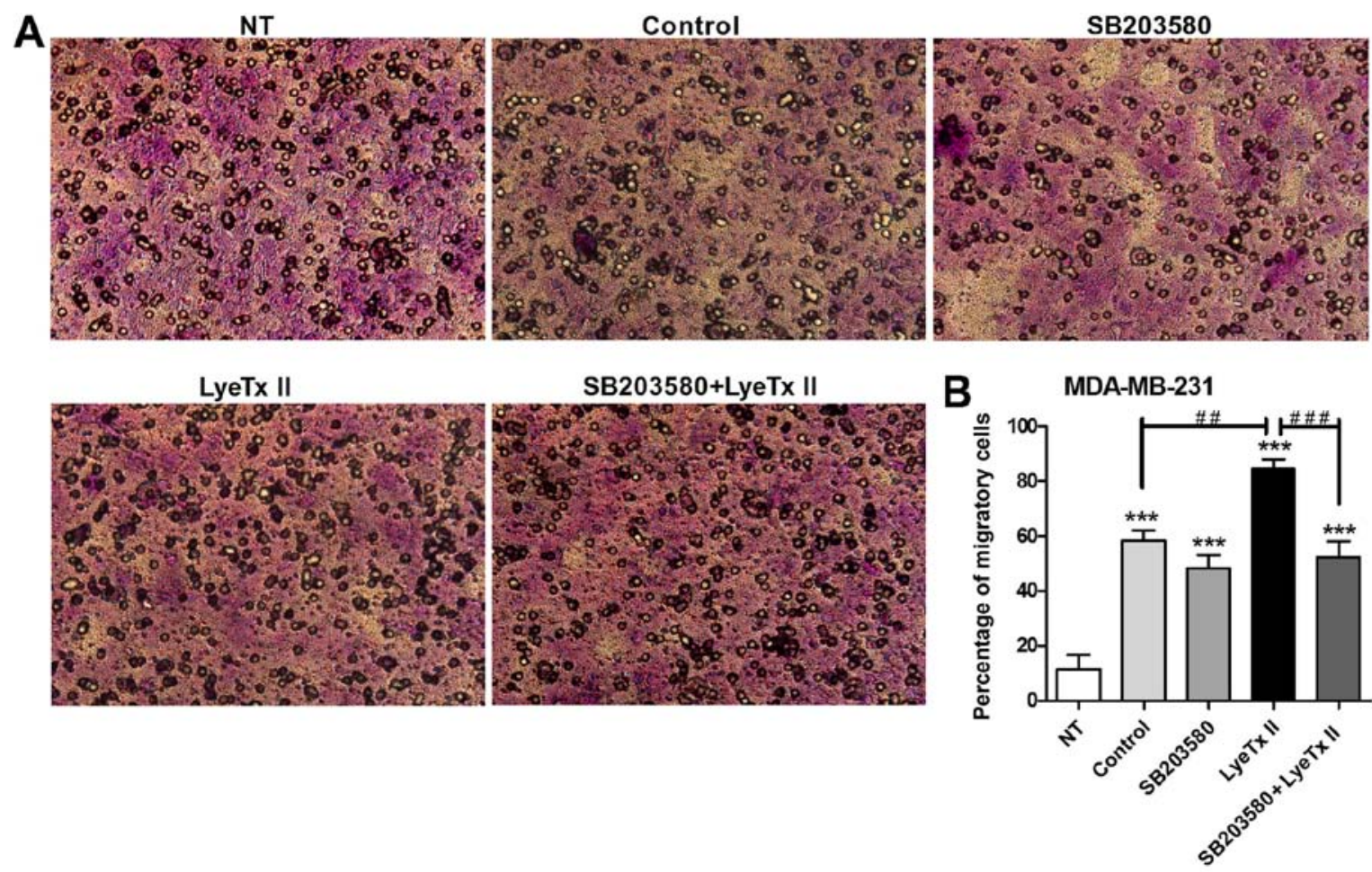

Figure 6. p38 inhibitor abrogates LyeTx II effect on MDA-MB-231 cell migration. (A) Cells were seeded on the upper chamber with serum-free medium in the presence or not of LyeTx II $(100 \mathrm{nM})$. SB203580 $(10 \mu \mathrm{M})$ was added in the upper chamber 30 min before LyeTx II treatment. DMEM with $10 \%$ FBS was added to the lower chamber as a chemoattractant. After $24 \mathrm{~h}$ of incubation, cells that passed through the membrane were counted in 5 visual fields of x 200 magnification of each membrane. (B) Graphic represents the media \pm SD of the percentage of cells that passed through the membrane after different treatments. Statistical analyses were performed using one-way ANOVA followed by Bonferroni post test. ${ }^{* * *} \mathrm{p}<0.001$ compared with non-treated (NT) group. ${ }^{\# \#}$ p $<0.01$;

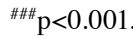

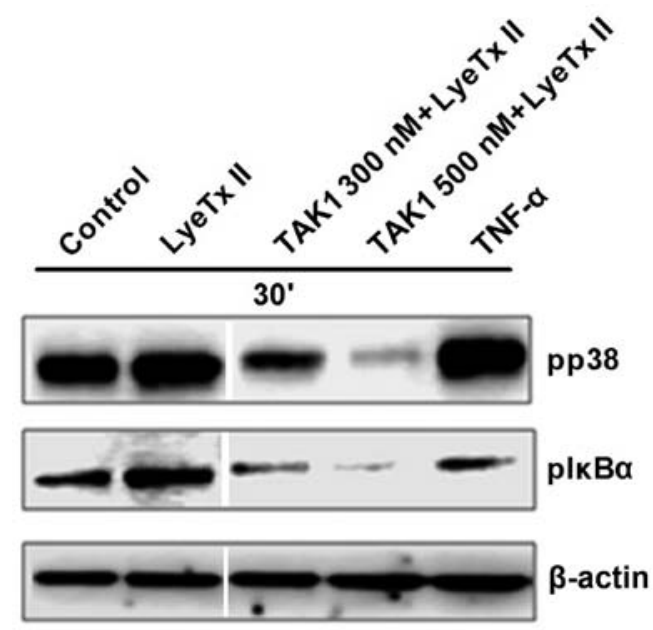

Figure 7. Impact of TAK1 inhibitor on $\mathrm{p} 38$ and $\mathrm{I} \kappa \mathrm{B} \alpha$ phosphorylation induced by LyeTx II peptide. MDA-MB-231 cells were pretreated or not with TAK1 inhibitor [(5Z)-7-oxozeaenol] and incubated for $30 \mathrm{~min}$ with LyeTx II at $100 \mathrm{nM}$ in DMEM supplemented with $10 \%$ FBS (Control = medium $10 \% \mathrm{FBS})$

It has also been reported that p38 may play an important role in many steps of metastasis, such as invasion/migration, in pancreatic, hepatocellular and head and neck squamous carcinoma cell lines on the basis of the use of SB203580 and dominant-negative mutants (36). Herein we demonstrated that LyeTx II, through upregulation of p38 phosphorylation, enhanced MDA-MB-231 cell migration, reinforcing the involvement of p38 in the augmentation of the aggressive character of the tumor cells.

We sought to define whether the increased proliferation was due to a combination of events involving proliferation and/or anti-apoptotic pathways. Given the role of the transcription factor NF-kB in prosurvival pathways (37), we analyzed the capacity of the peptide to upregulate the NF- $\mathrm{kB}$ pathway. At first, it was of interest to note that while MDA-MB-231 cells were capable of phosphorylating IKK- $\alpha \beta$ and IкB $\alpha$ in the presence of serum, MCF-7 did not (data not shown). This is in accord with a model proposed by Lee et al (38) where ER breast cancer cells, such as MDA-MB-231, use constitutively $\mathrm{NF}-\kappa \mathrm{B}$ pathway and $\mathrm{ER}^{+}$breast cancer cells, such as MCF-7, do not. The peptide activity fits this model by enhancing IKK- $\alpha \beta$ and I $\kappa \mathrm{B} \alpha$ phosphorylation only in MDA-MB-231 cells. This suggests that LyeTx II, besides its proliferative activity, might play a pro-survival role through upregulation of NF- $\mathrm{BB}$ pathway. This might explain the significant impact of this peptide on MDA-MB-231 cell proliferation and migration at low concentration (approximately $100 \mathrm{nM}$ ). Peptides used in cancer studies act generally at concentration superior to $1 \mu \mathrm{M}(39,40)$.

Considering that LyeTx II modulated p38 and NF- $\kappa \mathrm{B}$ pathways activation, we hypothesized that a common molecule could regulate both pathways in response to the peptide. TAK1 has been reported as an upstream kinase of p38 and NF- $\mathrm{B}$ (41-43), so it appeared relevant in our model to correlate $\mathrm{p} 38$ and IкB $\alpha$ activation with TAK1 activity. Our data suggest that the phosphorylation of $\mathrm{p} 38$ and $\mathrm{I} \kappa \mathrm{B} \alpha$ is dependent 
on TAK1 activation. Noteworthy, it has been reported that p38 may exert a positive feedback on TAK1 phosphorylation (44), which may occur in our model since a sustained phosphorylation of p38 has been observed in presence of LyeTx II. Such feedback mechanism may contribute to the peptide activity.

An interesting finding in this study was the divergence of cellular response between the non-aggressive MCF-7 and aggressive MDA-MB-231 tumor cells to LyeTx II, probably due to the differential use of signaling pathways by cell lines. Comparative phosphoproteosome analysis reveals differences in levels of various phosphoproteins in these two cell lines (45). This indicates that the sole presence or lack of receptors (ER, PR, HER2) may not be sufficient to classify tumor cells and to predict treatment.

In conclusion, we were able to associate a dysregulation of MAPK signaling pathways with a specific breast tumor cell function. We identified, by using the synthetic peptide LyeTx II, that upregulation of the p38 pathway in a TAK1dependent manner led to an accelerated proliferation and migration rate in MDA-MB-231 cells. This study highlights the importance of using compounds derived from animal venoms that may contribute to identify new targets for breast cancer treatment. Furthermore, these data open new perspectives for the use of $\mathrm{p} 38$ and TAK1 inhibitors as a targeted-treatment in cancer.

\section{Acknowledgements}

This study was funded by Fundação de Amparo à Pesquisa do Estado de Minas Gerais (FAPEMIG) (grant no.536-APQ-01682-13), Conselho Nacional de Desenvolvimento Científico e Tecnológico (CNPq), CAPES (Coordenação de Aperfeiçoamento de Pessoal de Nível Superior) and INCTTOX (Instituto Nacional de Ciência e Tecnologia em Toxinas). H.W.H. is a Ph.D. student fellow from CAPES. D.M.S. and H.D.G are post-doc and Ph.D. research fellows from CNPq and CAPES, respectively. C.R. is senior researcher from CNPq. M.E.L. is a professor and has received grants from the cited agencies. The authors thank the Program for Technological Development in Tools for Health-PDTIS - FIOCRUZ (Belo Horizonte, Minas Gerais, Brazil) for use of its facilities. We are grateful to Professor Aristóbolo Mendes (Depto. de Morfologia; UFMG; Brazil) Professor D. Gomes (Depto. Bioquímica Imunologia; UFMG; Brazil) for use of their laboratory facilities.

\section{References}

1. Banerji B, Pramanik SK, Pal U and Maiti NC: Potent anticancer activity of cystine-based dipeptides and their interaction with serum albumins. Chem Cent J 7: 91, 2013.

2. Misale S, Yaeger R, Hobor S, Scala E, Janakiraman M, Liska D, Valtorta E, Schiavo R, Buscarino M, Siravegna G, et al: Emergence of KRAS mutations and acquired resistance to anti-EGFR therapy in colorectal cancer. Nature 486: 532-536, 2012.

3. Diaz LA Jr, Williams RT, Wu J, Kinde I, Hecht JR, Berlin J, Allen B, Bozic I, Reiter JG, Nowak MA, et al: The molecular evolution of acquired resistance to targeted EGFR blockade in colorectal cancers. Nature 486: 4-7, 2012.

4. Dhillon AS, Hagan S, Rath O and Kolch W: MAP kinase signalling pathways in cancer. Oncogene 26: 3279-3290, 2007.

5. Roberts PJ and Der CJ: Targeting the Raf-MEK-ERK mitogenactivated protein kinase cascade for the treatment of cancer. Oncogene 26: 3291-3310, 2007.
6. Boutros T, Chevet E and Metrakos P: Mitogen-activated protein (MAP) kinase/MAP kinase phosphatase regulation: Roles in cell growth, death, and cancer. Pharmacol Rev 60: 261-310, 2008.

7. Kyriakis JM and Avruch J: Mammalian MAPK signal transduction pathways activated by stress and inflammation: A 10-year update. Physiol Rev 92: 689-737, 2012.

8. Cargnello $\mathrm{M}$ and Roux PP: Activation and function of the MAPKs and their substrates, the MAPK-activated protein kinases. Microbiol Mol Biol Rev 75: 50-83, 2011.

9. Samatar AA and Poulikakos PI: Targeting RAS-ERK signalling in cancer: Promises and challenges. Nat Rev Drug Discov 13: 928-942, 2014.

10. Igea A and Nebreda AR: The stress kinase p38 $\alpha$ as a target for cancer therapy. Cancer Res 75: 3997-4002, 2015.

11. Koul HK, Pal M and Koul S: Role of p38 MAP kinase signal transduction in solid tumors. Genes Cancer 4: 342-359, 2013.

12. Wagner EF and Nebreda AR: Signal integration by JNK and p38 MAPK pathways in cancer development. Nat Rev Cancer 9: 537-549, 2009.

13. Tournier C: The 2 faces of JNK signaling in cancer. Genes Cancer 4: 397-400, 2013.

14. Hoesel B and Schmid JA: The complexity of NF- $\kappa$ B signaling in inflammation and cancer. Mol Cancer 12: 86, 2013.

15. Gyrd-Hansen M and Meier P: IAPs: From caspase inhibitors to modulators of NF-kappaB, inflammation and cancer. Nat Rev Cancer 10: 561-574, 2010.

16. Sung B, Prasad S, Yadav VR and Aggarwal BB: Cancer cell signaling pathways targeted by spice-derived nutraceuticals. Nutr Cancer 64: 173-197, 2012.

17. Erstad DJ and Cusack JC Jr: Targeting the NF- $\kappa$ B pathway in cancer therapy. Surg Oncol Clin N Am 22: 705-746, 2013.

18. Gilmore TD: Introduction to NF-kappaB: Players, pathways, perspectives. Oncogene 25: 6680-6684, 2006.

19. Santos DM, Verly RM, Piló-Veloso D, de Maria M, de Carvalho MA, Cisalpino PS, Soares BM, Diniz CG, Farias LM, Moreira DF, et al: LyeTx I, a potent antimicrobial peptide from the venom of the spider Lycosa erythrognatha. Amino Acids 39: 135-144, 2010.

20. Correa CR, Bertollo CM and Goes AM: Establishment and characterization of MACL-1 and MGSO-3 cell lines derived from human primary breast cancer. Oncol Res 17: 473-482, 2009.

21. Pierce JW, Schoenleber R, Jesmok G, Best J, Moore SA, Collins T and Gerritsen ME: Novel inhibitors of cytokine-induced IkappaBalpha phosphorylation and endothelial cell adhesion molecule expression show anti-inflammatory effects in vivo. J Biol Chem 272: 21096-21103, 1997.

22. Bain J, Plater L, Elliott M, Shpiro N, Hastie CJ, McLauchlan H, Klevernic I, Arthur JS, Alessi DR and Cohen P: The selectivity of protein kinase inhibitors: A further update. Biochem J 408: 297-315, 2007.

23. Clark K, Nanda S and Cohen P: Molecular control of the NEMO family of ubiquitin-binding proteins. Nat Rev Mol Cell Biol 14: 673-685, 2013.

24. Martin SE, Wu ZH, Gehlhaus K, Jones TL, Zhang YW, Guha R, Miyamoto S, Pommier Y and Caplen NJ: RNAi screening identifies TAK1 as a potential target for the enhanced efficacy of topoisomerase inhibitors. Curr Cancer Drug Targets 11: 976-986, 2011.

25. Safina A, Ren MQ, Vandette E and Bakin AV: TAK1 is required for TGF-beta 1-mediated regulation of matrix metalloproteinase-9 and metastasis. Oncogene 27: 1198-1207, 2008.

26. Chen L, Mayer JA, Krisko TI, Speers CW, Wang T, Hilsenbeck SG and Brown PH: Inhibition of the p38 kinase suppresses the proliferation of human ER-negative breast cancer cells. Cancer Res 69: 8853-8861, 2009

27. Leelahavanichkul K, Amornphimoltham P, Molinolo AA, Basile JR, Koontongkaew S and Gutkind JS: A role for p38 MAPK in head and neck cancer cell growth and tumor-induced angiogenesis and lymphangiogenesis. Mol Oncol 8: 105-118, 2014.

28. Kummer JL, Rao PK and Heidenreich KA: Apoptosis induced by withdrawal of trophic factors is mediated by p38 mitogenactivated protein kinase. J Biol Chem 272: 20490-20494, 1997.

29. Bulavin DV, Kovalsky O, Hollander MC and Fornace AJ Jr: Loss of oncogenic H-ras-induced cell cycle arrest and p38 mitogenactivated protein kinase activation by disruption of Gadd45a. Mol Cell Biol 23: 3859-3871, 2003.

30. She QB, Bode AM, Ma WY, Chen NY and Dong Z: Resveratrolinduced activation of p53 and apoptosis is mediated by extracellular-signal-regulated protein kinases and p38 kinase. Cancer Res 61: 1604-1610, 2001. 
31. Mikhailov A, Shinohara M and Rieder CL: Topoisomerase II and histone deacetylase inhibitors delay the G2/M transition by triggering the p38 MAPK checkpoint pathway. J Cell Biol 166 : 517-526, 2004

32. Bulavin DV, Amundson SA and Fornace AJ: p38 and Chk1 kinases: Different conductors for the $\mathrm{G}(2) / \mathrm{M}$ checkpoint symphony. Curr Opin Genet Dev 12: 92-97, 2002.

33. Thornton TM and Rincon M: Non-classical p38 map kinase functions: Cell cycle checkpoints and survival. Int J Biol Sci 5 : 44-51, 2009.

34. Huth HW, Albarnaz JD, Torres AA, Bonjardim CA and Ropert C: MEK2 controls the activation of MKK3/MKK6-p38 axis involved in the MDA-MB-231 breast cancer cell survival: Correlation with cyclin D1 expression. Cell Signal 28: 1283-1291, 2016.

35. Schieven GL: The biology of $\mathrm{p} 38$ kinase: A central role in inflammation. Curr Top Med Chem 5: 921-928, 2005.

36. del Barco Barrantes I and Nebreda AR: Roles of p38 MAPKs in invasion and metastasis. Biochem Soc Trans 40: 79-84, 2012.

37. Pal S, Bhattacharjee A, Ali A, Mandal NC, Mandal SC and Pal M: Chronic inflammation and cancer: potential chemoprevention through nuclear factor kappa B and p53 mutual antagonism. J Inflamm (Lond) 11: 23, 2014.

38. Lee ST, Li Z, Wu Z, Aau M, Guan P, Karuturi RKM, Liou YC and $\mathrm{Yu}$ Q: Context-specific regulation of $\mathrm{NF}-\kappa \mathrm{B}$ target gene expression by EZH2 in breast cancers. Mol Cell 43: 798-810, 2011.
39. Han R, Liang H, Qin ZH and Liu CY: Crotoxin induces apoptosis and autophagy in human lung carcinoma cells in vitro via activation of the p38MAPK signaling pathway. Acta Pharmacol Sin 35: 1323-1332, 2014

40. Liu Z, Zhao Y, Li J, Xu S, Liu C, Zhu Y and Liang S: The venom of the spider Macrothele raveni induces apoptosis in the myelogenous leukemia K562 cell line. Leuk Res 36: 1063-1066, 2012.

41. Ninomiya-Tsuji J, Kishimoto K, Hiyama A, Inoue J, Cao Z and Matsumoto K: The kinase TAK1 can activate the NIK-I kappaB as well as the MAP kinase cascade in the IL-1 signalling pathway. Nature 398: 252-256, 1999.

42. McDermott EP and O'Neill LA: Ras participates in the activation of p38 MAPK by interleukin-1 by associating with IRAK, IRAK2, TRAF6, and TAK-1. J Biol Chem 277: 78087815,2002

43. Mihaly SR, Ninomiya-Tsuji J and Morioka S: TAK1 control of cell death. Cell Death Differ 21: 1667-1676, 2014.

44. Sakurai H: Targeting of TAK1 in inflammatory disorders and cancer. Trends Pharmacol Sci 33: 522-530, 2012.

45. Kabir MH, Suh EJ and Lee C: Comparative phosphoproteome analysis reveals more ERK activation in MDA-MB-231 than in MCF-7. Int J Mass Spectrom 309: 1-12, 2012. 